\title{
Trends in drought occurrence and severity at mid-latitude European stations (1951-2015) estimated using standardized precipitation (SPI) and precipitation and evapotranspiration (SPEI) indices
}

\author{
Paulina Dukat $^{1}$ (D) $\cdot$ Ewa Bednorz $^{2}$ (D) $\cdot$ Klaudia Ziemblińska $^{1}$ (D) Marek Urbaniak $^{1}$ (D)
}

Received: 9 March 2020 / Accepted: 2 January 2022 / Published online: 22 January 2022

(c) The Author(s) 2022

\begin{abstract}
One of the negative consequences of climate change is the also increase in the severity, frequency and length of droughts appearing in Europe. The effects of meteorological drought are often substantial, not only for the natural environment but also for humans. Hence, the main purpose of this research was to determine the trends in the severity and occurrence of droughts in Europe during the period 1951-2015 using the standardized precipitation index and the standardized precipitation and evapotranspiration index (SPEI). For six European sites located in mid latitudes, the number of dry months was determined and the trend of their occurrence was examined. Moreover, for the summer months in which the indicators fell below 0 , the trend related to the severity of the drought was determined for each site. Despite the absence of a statistically significant trend of an increase in the occurrence of dry months in general, an increase in the severity of droughts occurring in summer was observed for the SPEI over a 6-month scale for all the investigated stations. The highest number of dry months since the 1970s appeared during the last 5 years of analysis.
\end{abstract}

\section{Introduction}

The 2009 report of the European Environment Agency (Collins et al. 2009) on the water resources in Europe stated that the relationship between the demand and availability of water has reached a critical point in many parts of the continent as a result of both excessive consumption of water and prolonged droughts. This has led to harmful effects on the functioning of freshwater ecosystems, such as decreases in the water levels of lakes and river flow as well as a reduction in the total surface area of wetlands, which is particularly important for the existence of local fauna. These effects are also accompanied by deterioration in water quality due to the

Responsible Editor: Stephanie Fiedler.

Paulina Dukat

paulina.dukat05@gmail.com

1 Meteorology Lab, Department of Construction and Geoengineering, Faculty of Environmental Engineering and Mechanical Engineering, Poznań University of Life Sciences, Piątkowska 94, 60-649 Poznań, Poland

2 Climatology Department, Adam Mickiewicz University in Poznań, Bogumiła Krygowskiego St. 10, 61-680 Poznań, Poland reduction of water resources. Climate changes will most certainly lead to further serious problems with water availability in the future and there will be more frequent and intense episodes of drought throughout Europe (Collins et al. 2009).

Drought is a natural event that occurs in all climates and is one of the most severe natural hazards that causes significant economic, social and environmental losses (Vogt and Somma 2000). At the end of the twentieth century and the beginning of the twenty-first century, significant parts of Europe were affected by drought (Lloyd-Hughes and Saunders 2002); in particular, the latter severe and prolonged droughts revealed the sensitivity of European ecosystems to this natural disturbance which was further intensified by human activities, such as disruption of the hydrological cycle by deforestation or improper drainage. More frequent occurrences of drought made the inhabitants of the European continent and the governments realize the risk of the many socioeconomic problems associated with water shortages, which resulted in activating a search for appropriate methods to mitigate the effects of drought. In the past 60 years, an increase in the frequency, duration, and intensity of droughts has already been observed in western, central, and southeastern Europe (Spinoni et al. 2016). Along with the changing climate, this trend is likely to strengthen further in the twenty-first century. In Europe in the period from 1976 to 
2006, economic losses related to drought were estimated at approximately 100 million euros (Vogt et al. 2011).

Different definitions of meteorological drought have been presented and used by authors depending on the scope and purpose of their research. For the present study, the definition of drought proposed in the IPCC report (Seneviratne et al. 2012a, b) was adopted. According to this definition, drought is a period of abnormally dry weather long enough to cause a serious hydrological imbalance. Thus, a period of anomalously low rainfall is defined as a meteorological drought. Water shortage, during the growing season, leads to the occurrence of an agricultural drought (due to the lack of moisture in the soil), while the reduction of water resources is defined as a hydrological drought (Seneviratne et al. 2012a, b). In addition to low rainfall, the occurrence of drought is associated with an increase in the actual rate of evapotranspiration. Lack of rainfall is the first factor favoring the occurrence of a meteorological drought, with this phenomenon enhanced by the potential increase in evapotranspiration reinforced by radiation, higher wind speed, and water vapor deficit due to temperature rises (Seneviratne et al. 2012a, b). It is now assumed that global warming and its regional aspects are one of the factors increasing the frequency of anomalous weather phenomena (IPCC 2001). Therefore, understanding the regional causes and the features of meteorological drought is important when investigating and understanding its specific impact (Trnka et al. 2016).

The variability of drought conditions can be assessed along with climatic changes using the standardized precipitation index (SPI), which uses precipitation totals only and thus can be used anywhere by simply transforming its skewed distribution to a normal distribution (Tsakiris and Vangelis 2005). The main advantage of the SPI is its simplicity, wherein the main disadvantage is the use of only one meteorological element to describe water deficit. This index has been used by many authors for the analysis of drought occurrences in Europe (Blain 2011; Krajinović 2010; Livada and Assimakopoulos 2007; LloydHughes and Saunders 2002), and in the United States (Hayes et al. 1999) where this index calculation method was developed (McKee and Nolan 1993, 1995). Since the input variable for the SPI is precipitation, rainfall increases or decreases will likely result in a wetting or drying tendency for the SPI, respectively. Nevertheless, in some countries rainfall variability plays a more important role than the average change: Poland is an example of a country where the SPI over a 12-month scale shows a slight wetting tendency despite a general decrease in precipitation (Spinoni et al. 2019). On the contrary, for small countries such as Oman or Tajikistan, where dry and semi-dry areas predominate, the results of SPI-12 calculations suggest a tendency toward drying, despite a slight increase in precipitation, so the SPI calculations may be biased.

The standardized precipitation evapotranspiration index (SPEI) is based on precipitation and potential evapotranspiration data (Vicente-Serrano et al. 2010), which, in principle, is a modification of the standardized precipitation index to include the impact of temperature. The SPEI, similarly to the SPI, is one of the most widely used drought indicators in Europe (Spinoni et al. 2015). Due to the fact that the SPEI includes the potential evaporation factor (PET), it is recommended especially as an indicator for monitoring agricultural drought. In principle, PET can be calculated using more or less complex models/equations, e.g. Thornthwaite (TH), FAO-56 Penman-Monteith (PM), Hargreaves-Samani (HG) (Bezdan et al. 2019) but simultaneously this is its biggest disadvantage. The Thornthwaite (TH) method is the simplest way to calculate potential evapotranspiration due to the factors used, which are easily accessible-average air temperature for the investigated period and the latitude of the location. Significant differences were found when the SPEI was calculated using different PET equations wherein the differences were bigger in semi-arid and mesic areas (Beguería et al. 2014).

\subsection{Hypotheses and aims}

Appropriate recognition of the climate features related to occurrences of drought in the past is crucial. In addition, proper monitoring and development of drought mitigation strategies using appropriate tools, including indicators, are required. Drought can be identified based on various variables depending on data availability. Thus, one of the most desirable tools for determining drought in the future and its subsequent mitigation is a method based on easily accessible data, which includes air temperature and precipitation as key elements. It is expected that there would be an increasing trend in the occurrence of drought, determined with the help of both the selected indicators. Climate change is visible, inter alia, by increasing global air temperature and changing precipitation distribution. We hypothesize that this can lead to an increase in the occurrence of drought, also in those parts of Europe for which this has not been a characteristic climate feature. Our main aim is thus to define trends in the frequency and severity of drought events for mid-latitude European countries using data from six meteorological stations located in this region covering both marine and continental temperate climate conditions.

\section{Materials and methods}

\subsection{Data}

For the meteorological station in Warsaw, data were obtained from the Institute of Meteorology and Water ManagementNational Research Institute, while for all other stations this was obtained from the Home European Climate Assessment \& Dataset portal (ECAD 2018). Average daily values of 
temperature and precipitation totals were used to calculate mean monthly air temperatures and monthly precipitation totals, respectively, which were then used to calculate the selected indices.

\subsection{Site descriptions}

The meteorological stations selected for the analysis are located in the mid latitudes of the European continent (Fig. 1). On the basis of the Koppen Geiger classification (Kottek et al. 2006), stations in Essen (Germany, $150 \mathrm{~m}$ above sea level [a.s.1.]), Berlin (Germany, $48 \mathrm{~m}$ a.s.l), Pécs (Hungary, $203 \mathrm{~m}$ a.s.l), and Warsaw (Poland, $110 \mathrm{~m}$ a.s.l.) were categorized as areas with a moderate warm and humid climate with an average temperature lower than $18{ }^{\circ} \mathrm{C}$ and higher than $-3{ }^{\circ} \mathrm{C}$ in the coldest month $(\mathrm{Cfb})$. The stations in Kiev (Ukraine, $166 \mathrm{~m}$ a.s.l) and Moscow (Russia, $156 \mathrm{~m}$ a.s.l) were categorized under the Dfb class, which is characterized as a snow-forest climate (boreal) with the coldest month having an average air temperature below $-3{ }^{\circ} \mathrm{C}$ and the warmest month having a temperature higher than $10{ }^{\circ} \mathrm{C}$
(Kożuchowski et al. 2012; Woś 2010). Long-term average air temperatures and the average precipitation totals for each site are shown in Table 1. Among the investigated stations, the highest long-term average annual temperature calculated for the period 1951-2015 occurred in Pécs, which was equal to $10.8^{\circ} \mathrm{C}$, while the lowest temperature occurred in the station in Moscow, which was $5.3{ }^{\circ} \mathrm{C}$ (Fig. 2, Table 1). The highest average annual precipitation total was measured in Essen (923 mm), while the lowest, estimated to be only $521 \mathrm{~mm}$, was recorded in the station in Poland. At all the stations, the highest precipitation occurred in the summer months: in June in Essen, Berlin and Moscow and in July in Pécs, Warsaw and Kiev (Fig. 2). From the perspective of climate type analysis, determined by means of the two meteorological elements (temperature and precipitation) on a monthly basis, it was evident that not only is the total precipitation value significant but also its distribution throughout the year. The standard deviation of the total monthly precipitation from the annual mean for the entire period (1951-2015) was the highest in Essen and Pécs. Lower values were found for the stations in Warsaw (31) and Berlin (30) (Table 1).
Fig. 1 Locations of the meteorological stations in Europe included in the research
Table 1 Mean annual precipitation total $(P)(\mathrm{mm})$ and mean annual air temperature $(C)$ for each station included in the research, SD—standard deviation from the period 1951-2015

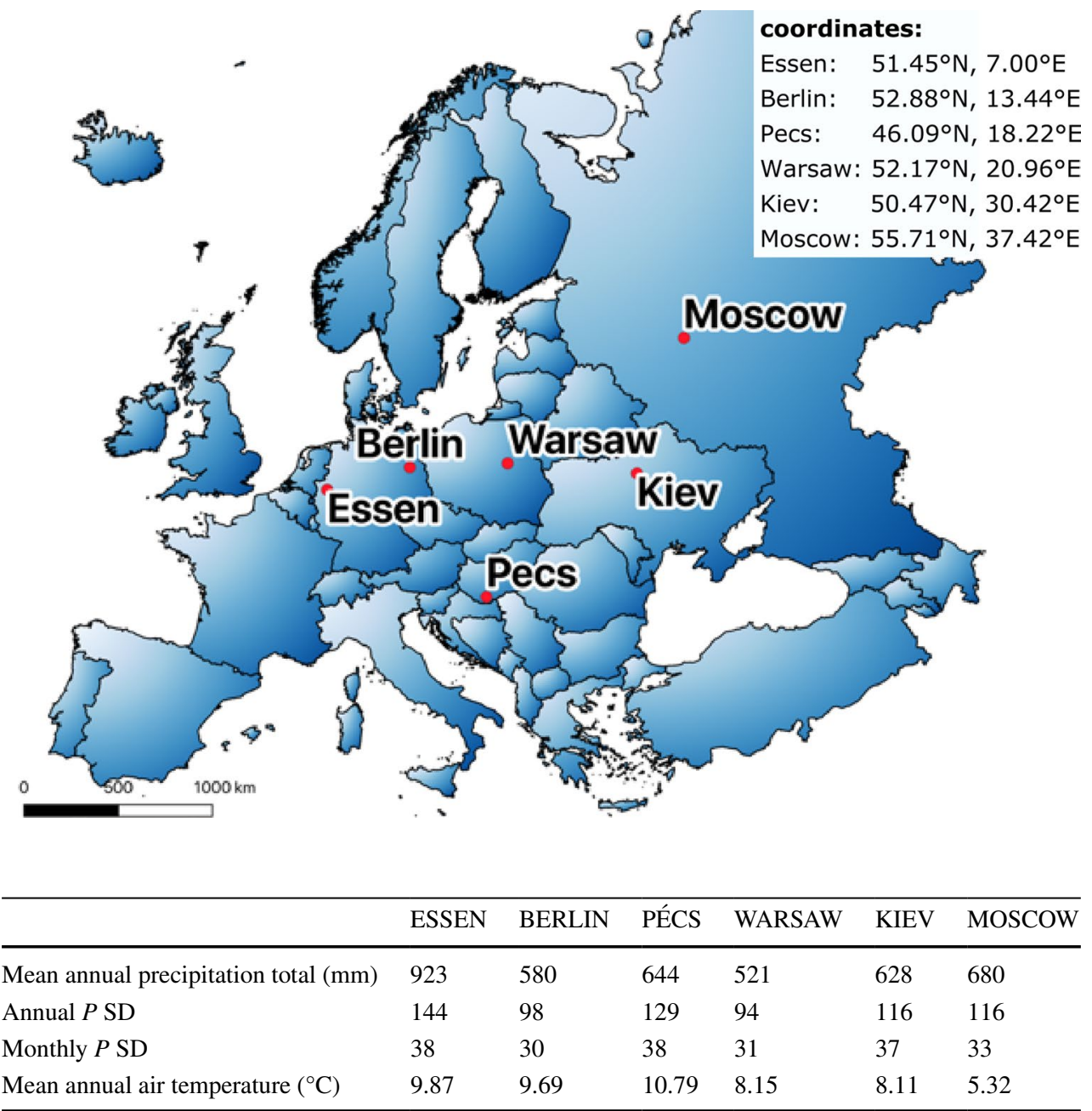



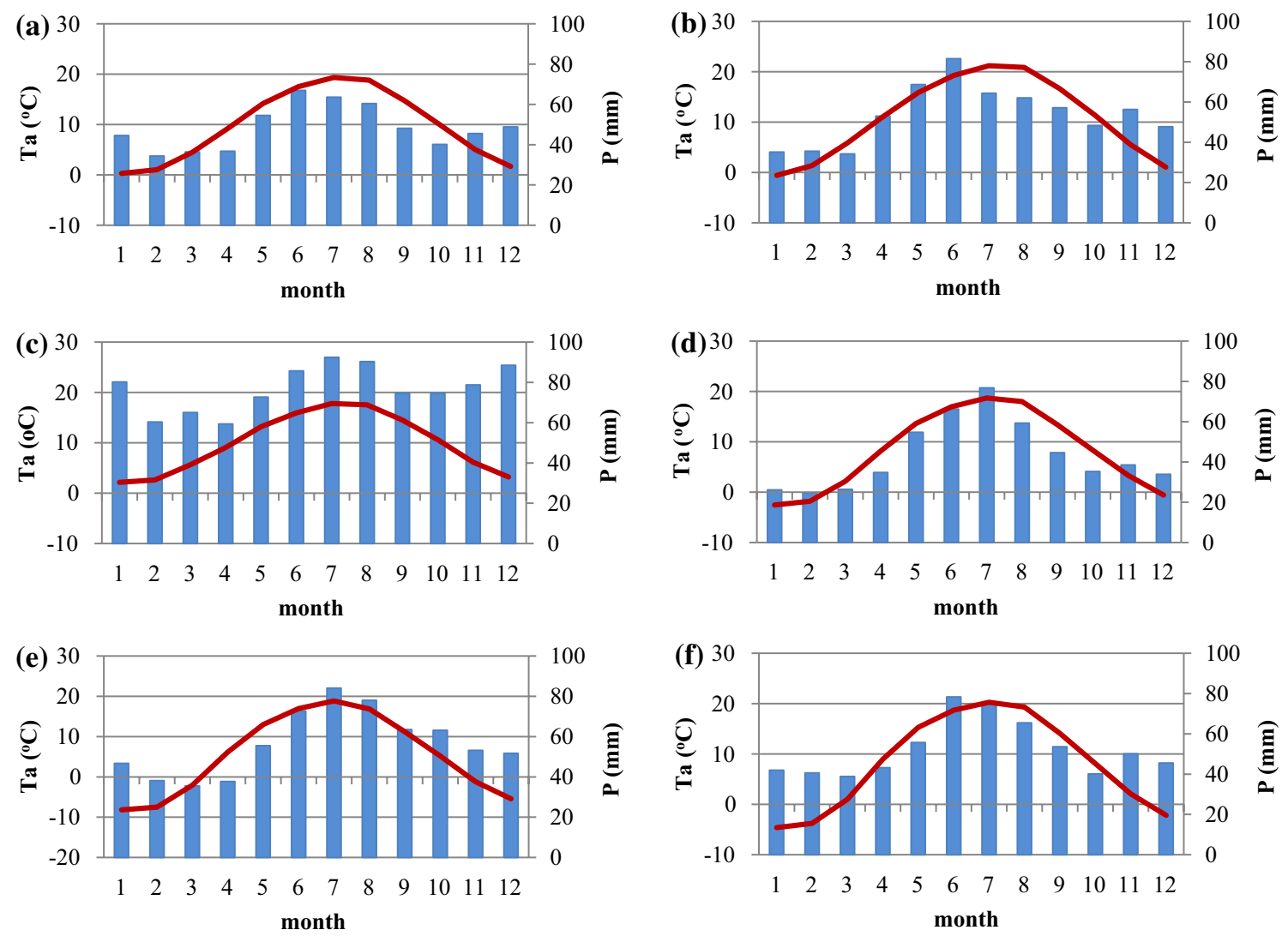

Fig. 2 Climatograms for a Essen, b Berlin, $\mathbf{c}$ Pécs, $\mathbf{d}$ Warsaw, e Kiev, and $\mathbf{f}$ Moscow, based on the data from the period 1951-2015. Ta average monthly air temperature $\left({ }^{\circ} \mathrm{C}\right)$ (red line), $P$ monthly precipitation totals $(\mathrm{mm})$

\subsection{Methods}

To determine the number of dry months in the analyzed period at each station, two indicators were used: SPI and SPEI. The SPI is calculated by fitting a probability density function to a given frequency distribution of historical precipitation (Faye et al. 2019) and then the probabilities are transformed into a normalized distribution with a mean equal to zero and a variance of one, which was developed by McKee and Nolan (1993, 1995). Originally, the SPI was calculated for 1-, 2-, 3-, 6-, 12-, 24-, 36-, and 48-month scales to recognize the different impacts, but in general this index can be calculated for any weekly or monthly timescale (Hayes et al. 2012). Because the SPI is normalized based on the statistical representation of historical records in each location separately, drought conditions can be recognized equally well for both humid and drier climate conditions. In addition, it can be used for assessing the severity of the drought and to issue warnings regarding the possibility of it occurring. The method to derive the SPEI index is based on the original SPI calculation procedure but includes an additional variable, i.e. potential evapotranspiration. It is recommended considering the thermal factor (here indirectly by the inclusion of PET in SPEI index), especially for applications such as the analysis of future climate scenarios which is useful for studying the effects of global warming and drought (Beguería et al. 2010; Vicente-Serrano et al. 2010).

Here, in order to calculate the SPEI index, the potential evapotranspiration was estimated according to the Thornthwaite equation (Thornthwaite 1948) (Eq. 1), which is part of the package "SPEI" in R software (version 3.5.0; The R Foundation for Statistical Computing, 2018/04/23). The variables used in the PET calculations presented below are the monthly precipitation totals, monthly mean air temperature and the latitude of the station's location. The exact methodology for calculating the SPEI has been presented by Vicente-Serrano et al. (2010).

PET $=16 K\left(\frac{10 T}{I}\right)^{m}$, 
where: $T$ is the mean monthly temperature $\left({ }^{\circ} \mathrm{C}\right) ; I$ is the heat index, which is calculated as the sum of the 12 monthly index values $i$ according to the following formula:

$i=\left(\frac{T}{5}\right)^{1.514}$,

$K$ is a correction coefficient computed as a function of the latitude and month (Vicente-Serrano et al. 2010) and $\mathrm{m}$ is a coefficient depending on $I$ :

$m=6.75 \times 10^{-7} I^{3}-7.71 \times 10^{-5} I^{2}+1.79 \times 10^{-2}+0.492$.

Vicente-Serrano et al. (2010) concluded that log-logistic distribution is the best option among other distributions for obtaining an SPEI series in standardized $z$ units (mean $=0$, $\mathrm{SD}=1$ ). Therefore, for the purposes of this study, standardization of the meteorological variables was also carried out by using a log-logistic distribution. The probability distribution function of monthly precipitation (SPI) or the difference between precipitation and potential evapotranspiration for each month (SPEI) is given by the equation described, for example, by (Beguería et al. 2014):

$F(D)=\left[1+\left(\frac{\alpha}{D-\gamma}\right)^{\beta}\right]^{-1}$,

where: $\alpha$ scale parameter, $\beta$ shape parameter, $\gamma$ location parameter, - all estimated from sample $D$, which for the SPEI is the difference between precipitation $(P)$ and potential evapotranspiration (PET).

After calculating the $\alpha, \beta$ and $\gamma$ parameters (the detailed methodology for calculating these is given by Singh et al. 1993), the unbiased probability weighted moments (PWMs) were calculated, based on a method described by Hosking (1986):

$w_{s}=\frac{1}{N} \sum_{i=1}^{N} \frac{\left(\begin{array}{c}N-i \\ s\end{array}\right) D_{i}}{\left(\begin{array}{c}N-i \\ s\end{array}\right)}$,

where $w_{s}$ is the PWM of order $s, N$ is the number of data and $D_{i}$ is the difference between precipitation $(P)$ and potential evapotranspiration (PET) for the month $i . D_{i}$ is therefore the climatic water balance (CWB).

Beguería et al. (2014) have suggested that the unbiased PWM method should be preferred for the computation of an SPEI series. When the two indicators are both normalized variables (the average SPI and SPEI values are 0 and the standard deviation is 1) they can be compared with other SPI and SPEI values, computed for different times and locations. A zero value of SPI or SPEI corresponds to $50 \%$ of the cumulative precipitation probability (SPI) or Climatic
Water Balance probability (SPEI), according to the logistic distribution (Vicente-Serrano et al. 2010). Each index value corresponds to the characteristic of the analyzed period (month); positive values of the SPI and SPEI indicate wetter months while negative ones-dry periods. McKee and Nolan (1993) proposed the following SPI categorization for conditions in Colorado (Table 2), which was applied in the presented study.

To calculate the SPI and SPEI, R software was used, in particular the "SPEI" package (Beguería and Vicente-Serrano $2017 \mathrm{a}, \mathrm{b}$ ). Corresponding indicator values were calculated for 1-,3- and 6-month scales since it was suggested that estimations of the occurrence of dry periods based on such time perspectives are appropriate for recognizing the impact of meteorological drought on agriculture (Rhee and Carbone 2010). Statistical calculations were determined using "base" and "ggplot" packages for preparing the figures. Drought occurrence, severity and trends have been analyzed using data outcome from SPEI package in $\mathrm{R}$ environment ( $\mathrm{R}$ Core Team 2020).

\section{Results and discussion}

\subsection{Temporal courses of climatic factors}

Due to climate changes and multidirectional anthropopressure, it is important to analyze trends occurring in the climatic system on both a global and local scale. Nevertheless, it should be emphasized that in case of multi-year research on climate-related trends, even less statistically significance trends may already be relevant for the climatic system. Due to the length of the period covered by the presented analysis, long-term trends in key meteorological elements, namely average annual air temperatures, annual precipitation totals and potential evapotranspiration, have been calculated according to the methodology presented above (Thornthwaite 1948), as well as deriving the climatic water balance (the difference between the annual precipitation total and the potential evapotranspiration), and are presented below (Fig. 3, Table 3).

Table 2 Classification of the months based on SPI index values ( source: Hayes et al. 1999 after McKee and Nolan 1993), also applicable for the SPEI index (Faustin Katchele et al. 2017; Wang et al. 2020)

\begin{tabular}{ll}
\hline Extremely dry & $<-2.0$ \\
Severely dry & -1.99 to -1.50 \\
Moderately dry & -1.49 to -1.00 \\
Near normal & -0.99 to 0.99 \\
Moderately wet & 1.00 to 1.49 \\
Very wet & 1.50 to 1.99 \\
Extremely wet & $>2.00$ \\
\hline
\end{tabular}


(a)

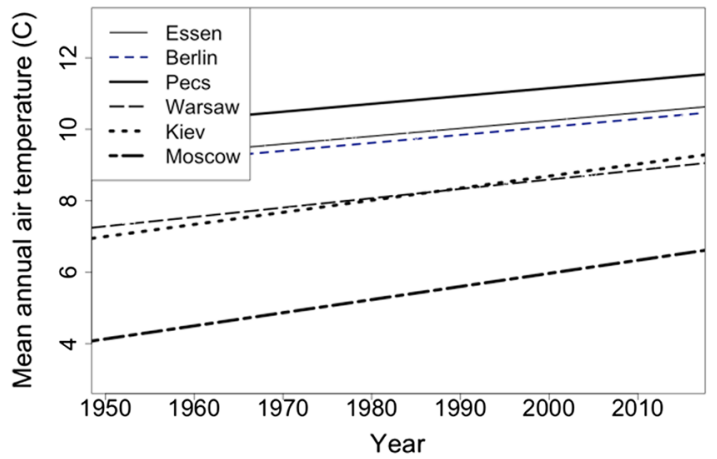

(b)

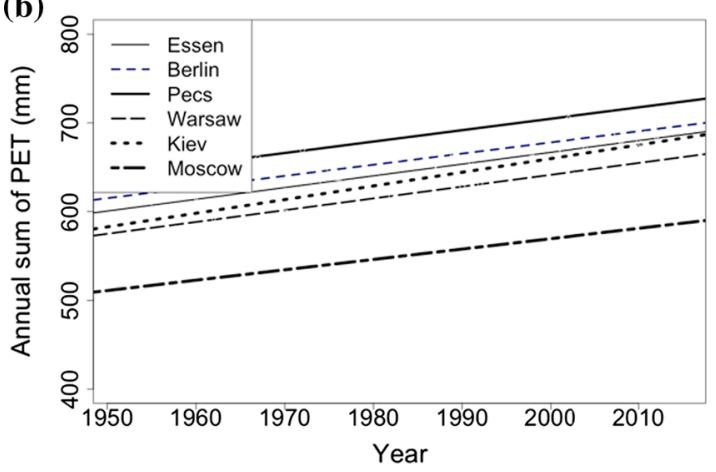

Fig. 3 Long-term trends of average annual air temperatures (a), annual potential evapotranspiration totals (b), annual climatic water balance totals (c), and annual precipitation totals (d), for all the inves- (c)

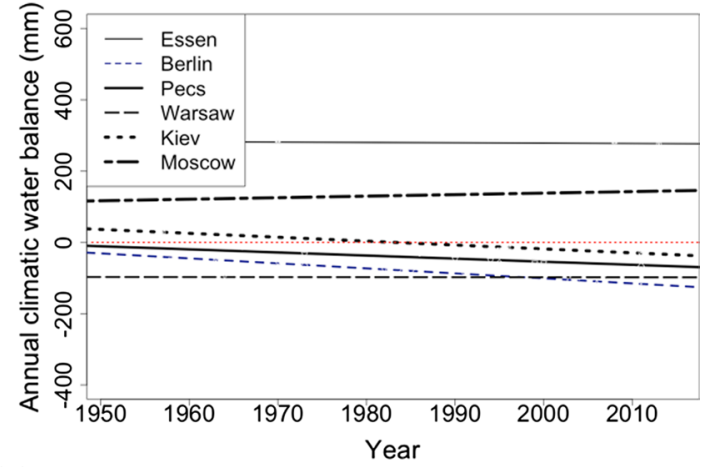

(d)

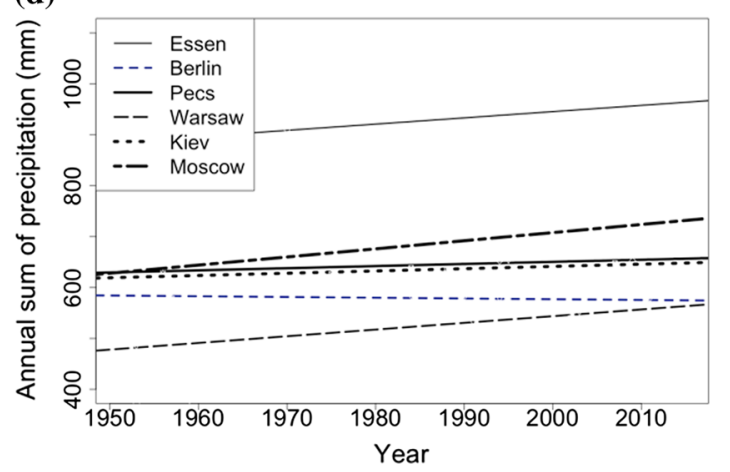

tigated European meteorological stations. The red dotted line in plot $\mathrm{c}$ represents the balance $=0$ between precipitation and PET
Table 3 Simple linear regression parameters fitted to the long-term data for the annual potential evapotranspiration (PET) total, the mean annual air temperature $(T)$ and the annual precipitation total (PREC) presented in Fig. 3

\begin{tabular}{lllllrr}
\hline & PET R $^{2}$ & PET $\boldsymbol{a}$ & $T R^{2}$ & $T a$ & PREC R $^{2}$ & PREC $\boldsymbol{a}$ \\
\hline ESSEN & 0.312 & 1.325 & 0.260 & 0.022 & 0.010 & 1.228 \\
BERLIN & 0.278 & 1.257 & 0.233 & 0.022 & -0.015 & -0.145 \\
PÉCS & 0.259 & 1.288 & 0.242 & 0.022 & -0.012 & 0.420 \\
WARSAW & 0.308 & 1.330 & 0.272 & 0.026 & 0.056 & 1.316 \\
KIEV & 0.333 & 1.540 & 0.360 & 0.034 & -0.011 & 0.445 \\
MOSCOW & 0.254 & 1.168 & 0.395 & 0.037 & 0.053 & 1.596 \\
\hline
\end{tabular}

$R^{2}$ coefficient of determination, calculated using Pearson's correlation, $a$ linear regression slope; significance level $\propto=0.005$
The performed analyses revealed that there is a positive trend for the average annual air temperature (Fig. 3a) and potential evapotranspiration (Fig. 3c) at all the stations included in this research. It turned out that during the last 60 years, the average annual air temperature has risen fastest in Moscow and Kiev. Simultaneously, the Russian station was also one of the two locations where the most significant positive trend of annual precipitation totals has been recorded. A negative trend of precipitation, even though quite insignificant in terms of its impact, was determined only for the Berlin meteorological station, and thus the annual amount of precipitation in that location can be expected to decrease in the future. 
There were no statically significant trends in the long-term climate water balance for any of the chosen European stations, therefore the corresponding parameters for the linear regression in this case are not shown in Table 2. Nevertheless, these trends are still shown in Fig. 3d, because this gives an idea of where to place particular stations in accordance with the threat of shrinking water resources (CWB $<0$ - too little precipitation to balance potential evapotranspiration).

\section{Long-term changes in the number of droughts}

The long-term (1951-2015) values of the SPI and SPEI indexes over 1-, 3-, and 6-month scales for all the stations are presented in the Figs. 8, 9, 10, 11, 12, 13 in Appendix 1. For Essen and Berlin, the analysis performed at 6-months revealed that according to both SPI and SPEI, in recent years (especially until the middle of the 2010-2015 pentad), the dominance of values below zero, suggesting a deviation toward dry conditions, is clearly visible. Certain cyclical deviations on this timescale were also recognized, with other periods of dry months in Germany, identified by both indicators. That conditions have been recognized at the beginning of the analyzed period: the 1950s, longer culmination in 1960 and before 1965, in Essen especially between 1970 and 1975 and before 1990, in Berlin after 1990 and especially in 2015 . For these sites, much wetter months were indicated in the 1980s and additionally for Essen at the beginning of the twenty-first century. In Pécs, analysis of the SPI values estimated over the same timescales allowed four especially dry periods to be distinguished: between 1955 and 1960, at the beginning of 1970, 1990 and also in 2011-2012. Meanwhile, according to the SPEI, assessment of the occurrence of dry conditions was generally similar to the SPI, but the increasing duration of dry months in 2011-2013 was much more pronounced. For Warsaw, both indicators show, over a 6-month timescale, drought periods at the beginning of the 1950s, before 1965, after 1975, at the beginning of the 1990s and at the end of the last pentad. On the other hand, during 1970-1975, in the early 1980s and the beginning of the last decade, the conditions were more humid in the Polish station. In Kiev, particularly long dry periods occurred during the 1955-1965 period and after 1975, according to both indicators. According to the SPI, the year 2015 and, according to the SPEI, the last five years were characterized by drier conditions in comparison with all other years. In Moscow, unusually long dry periods determined by both indicators over a 6-month timescale occurred in 1960-1965 and then for 1995-1997. During the last 20 years, the values of the SPEI index suggest the occurrence of much drier conditions in 2010-2012 and in 2015 , similarly to that estimated using the SPI, although with higher severity. Despite the quite large dispersion of the stations in the mid latitudes of Europe, similar fluctuations/periodicity were noticeable among all the investigated locations. In general, both indicators suggested that dry periods occurred mostly at the beginning and at the end of period covered by the analysis.

Using the 3-month SPI and SPEI index values, surface plots were created by dividing the plane into regular hexagons. Then, the number of observations in each hexagon was counted and finally mapped to fill the hexagons (Fig. 4). Such a graphical presentation of the results allows, for example, during the long-term period when the indicators were spread over a wider spectrum of values, to show whether and when the number of occurrences shifted toward negative values.

Compared to the other stations, Kiev had the largest concentration of values around 0 , according to the SPI index. In Berlin and Warsaw, during the most recent years, the distribution of the SPEI index has moved to more negative values, which means drier conditions. In Moscow, the number of occurrences of extremely dry months (SPEI index values close to -2 ) is also currently increasing compared to previous years, and approaching the value from before the 1960s. The irregular shapes obtained for the SPI index show, as previously stated, similarly irregular distributions for the precipitation factor. In Essen and Berlin, however, an increase in the severity of drought conditions in recent years can already be seen. Only in case of Moscow does the SPI index show an increase in the number of months characterized by wetter conditions, which most likely resulted from a similar long-term precipitation trend (Fig. 3b). For Pécs and Warsaw, broadening of the spectrum of SPEI index values has been found. This is associated with a flattening of the SPEI density distribution, which is the anticipated consequence of climate change - an increase in the number of extreme events.

\subsection{Trends in the occurrence of drought}

In the following section, trends in the occurrence of drought in the six different locations with a temperate climate on the continent of Europe covered by the analysis were determined. All the months in which the SPI and SPEI indexes 
Fig. 4 Distribution of the SPI (on the left) and SPEI (on the right) values for a 3-month scale presented on hexagonal surface plots for the six European meteorological stations: a Essen,

b Berlin, c Pécs, d Warsaw, e Kiev, and $\mathbf{f}$ Moscow
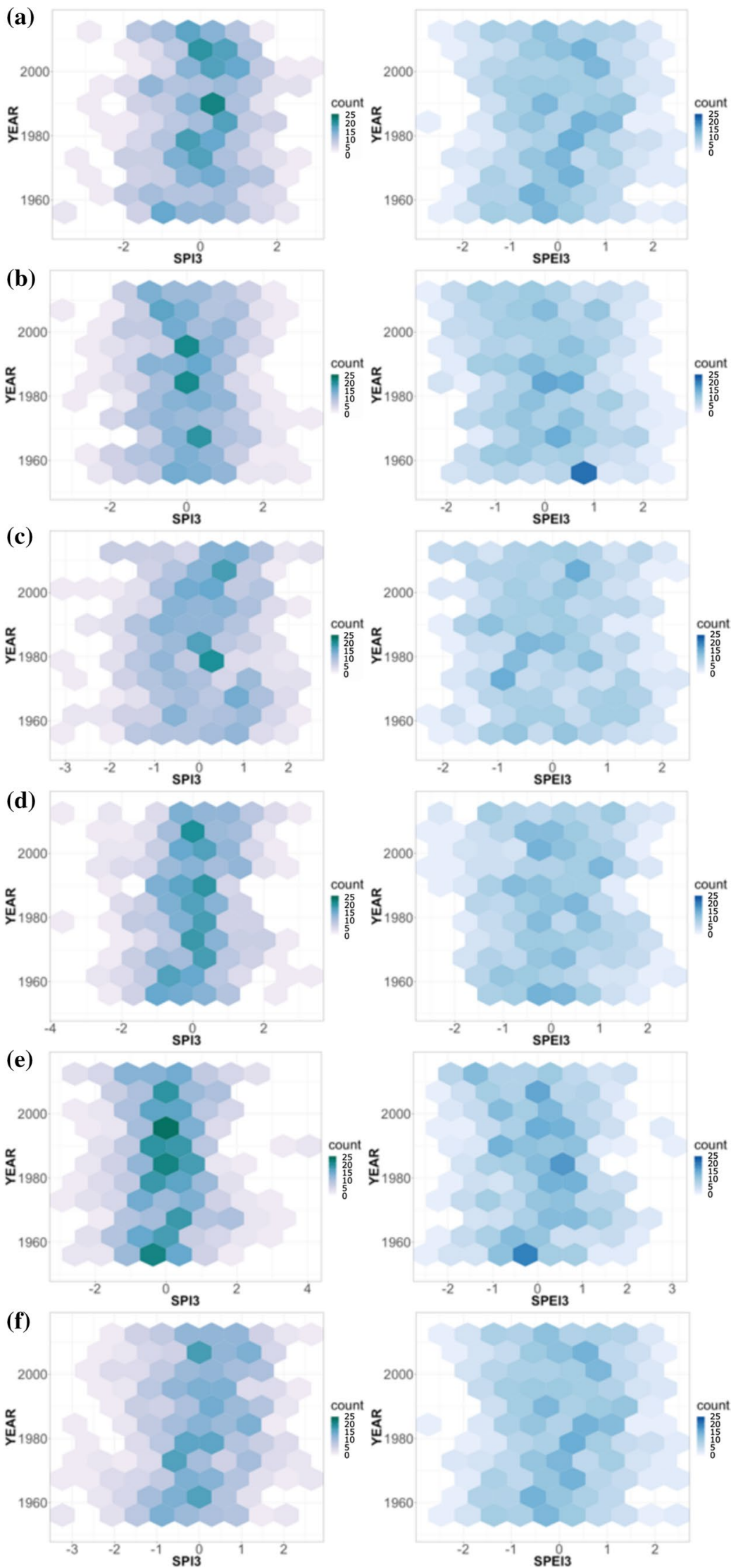

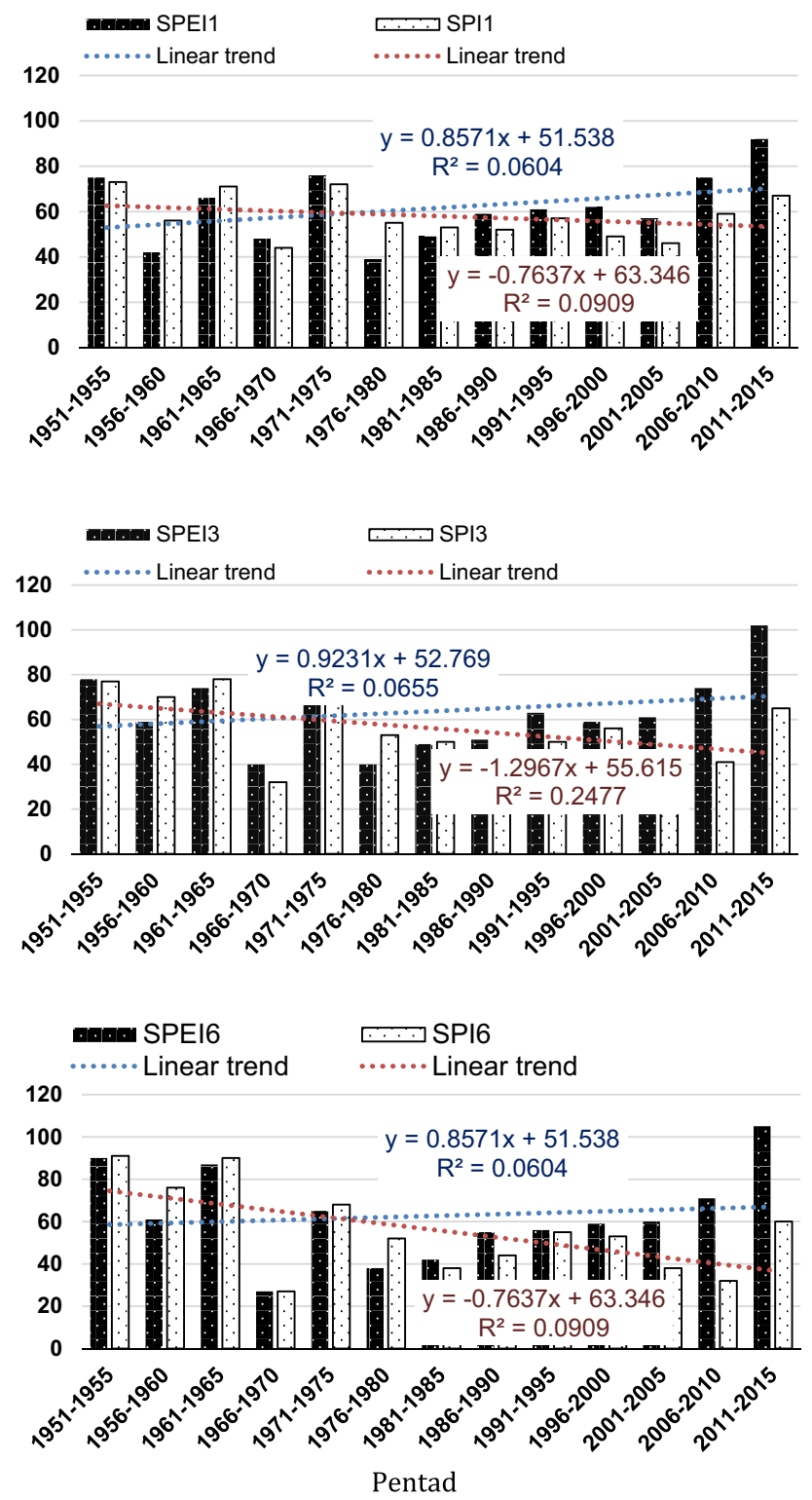

Fig. 5 Number of months in which the SPEI and SPI, calculated at 1-, 3- and 6-month timescales, fell below - 1.00. The figures given by the bars are the total numbers of dry periods in the pentads for all stations

fell below - 1 were added up for each site, which according to the classification (McKee and Nolan 1993) means drought-representative conditions (see Table 2). In order to show trends, the analyzed period was divided into pentads (Fig. 5). According to both indicators for all timescales (1-, 3- and 6-month perspectives), there are, in general, three periods in which the number of droughts in relation to the other 5-year periods was higher. For the SPEI index, these periods were: 1951-1956, 1961-1966 and 2010-2015 for all timescales, and additionally for the 1-month timescale during 1971-1976. Moreover, it should be emphasized that such presentation of the obtained results (aggregation of all the dry months from all the stations during 5-year periods) helps to show that there is a slight negative linear trend in the SPI index for all the timescales, which suggests a decrease in the number of droughts in the analyzed region. Analyzing the data on a monthly basis due to the large number of droughts in 1951-1966 (SPI), we found a lack of statistically significant trends in the occurrence of dry months within the studied period, which very likely has a large impact on the linear trend estimation. On the contrary, the SPEI index indicates an upward trend in drought occurrence regardless of the timescale. The most pronounced upward trend was found for the SPEI for a 3-month timescale. The possible explanation might already be in the increasing trend of the potential evapotranspiration totals in this part of Europe (Fig. 3). Figure 5 shows that in the last pentad (2011-2015) there were more dry months than in any other periods since 1976 as indicated by both the SPI and SPEI. For the SPEI for all three timescales, the number of droughts recorded in the last five years of the analyzed period significantly exceeded the earlier occurrences of this phenomenon.

\subsection{Trends in drought severity}

Index values below -1 , according to the adopted classification for the SPI and SPEI indices, detect the beginning of moderately dry conditions, which was the threshold used to estimate drought occurrence trends in the previous chapter. Whereas drought severity trends were derived by subtracting all negative SPEI and SPI index values from 0 for each station, which designates all drier than normal conditions in the chosen period. Afterwards, linear trends were calculated for both drought indicators at 1-, 3- and 6-month timescales, which, as they approach lower, negative values, indicate an increase in the severity of the drought (Fig. 6). Detailed information on these linear regression parameters is not presented here since they had very low values and were not statistically significant. An increasing trend in the severity of droughts for the SPEI and SPI indicators in the summer was recognized for the 1-month timescale in Essen, Berlin and Pécs, while in Essen and Berlin the upward trend of the SPEI was much more pronounced in comparison with 

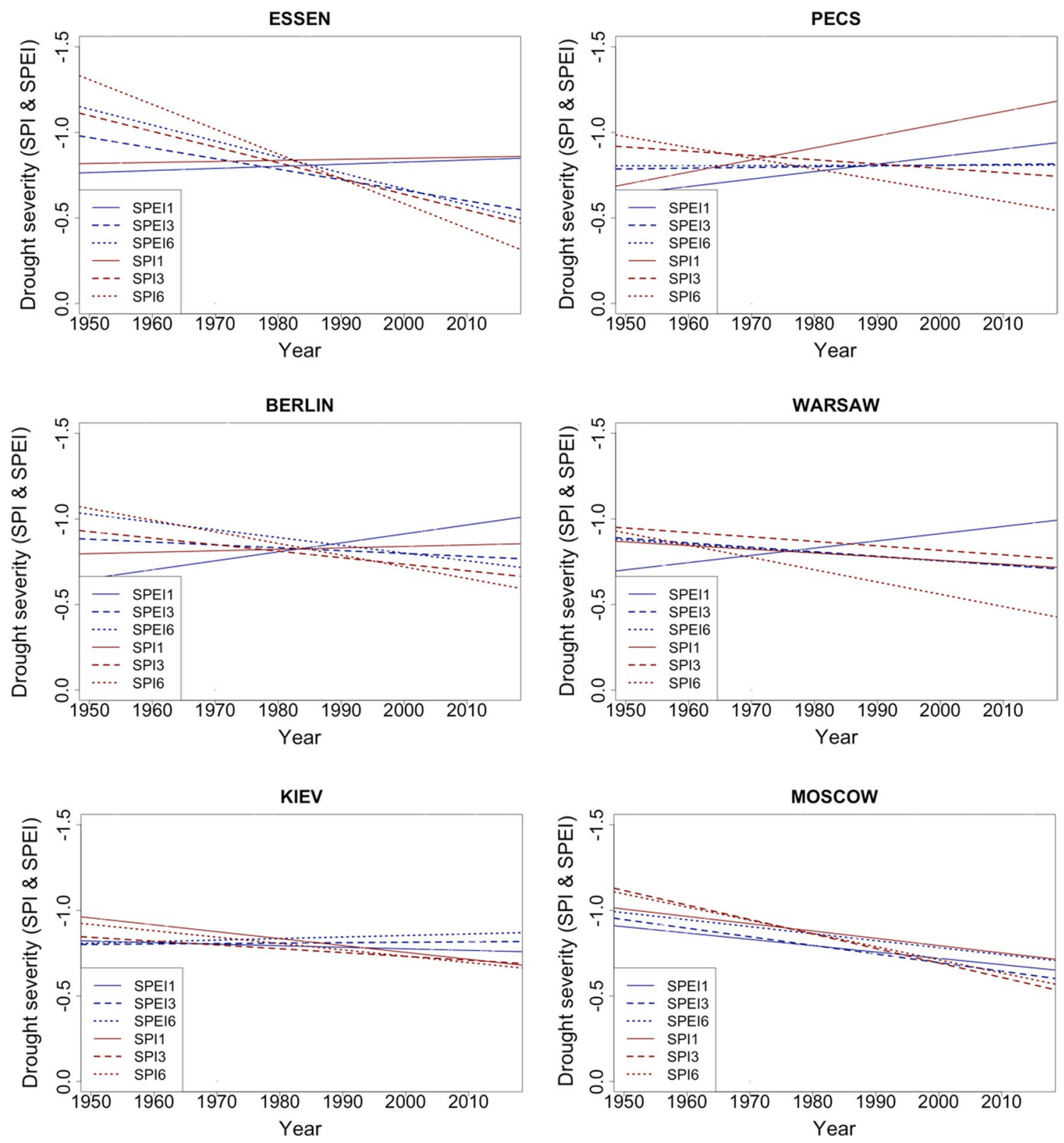

Fig. 6 Trends in drought severity for all stations included in the analysis. The lower the indicator value, the higher the severity of the drought

Pécs. In Kiev, a weak increasing trend of drought severity appeared for the SPEI for the 3- and 6-month timescales. In Warsaw, however, the increase in drought severity was pronounced only for the SPEI index for the 1-month timescale. The most consistent results were obtained for Moscow-all trend lines had similar courses with positive slopes for both the SPI and SPEI for all timescales, which suggests that there is a persistent tendency toward wetter conditions.
Considering that in Central and Eastern Europe droughts are the most dangerous for crops and other vegetation as well human wellbeing in the summer, similar linear trends of drought severity for June to August were investigated (Fig. 7, Table 4). This analysis included only the SPEI index calculated for the 3-month timescale since temperature plays a crucial role in the summer, and the "severity analysis" for the indicator based on precipitation only (SPI) 
(a)

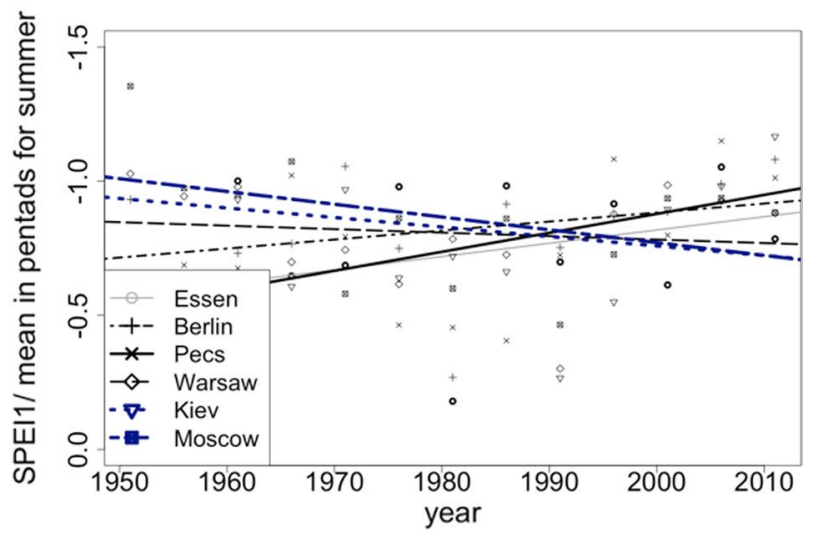

(b)

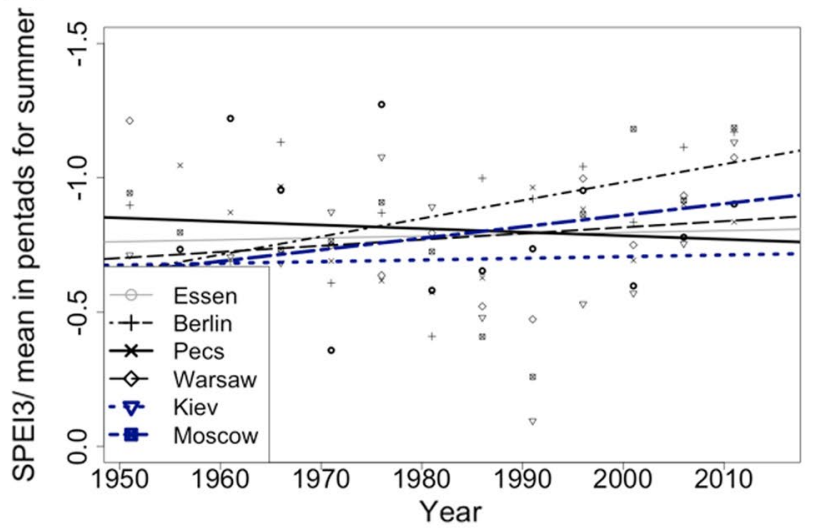

(c)

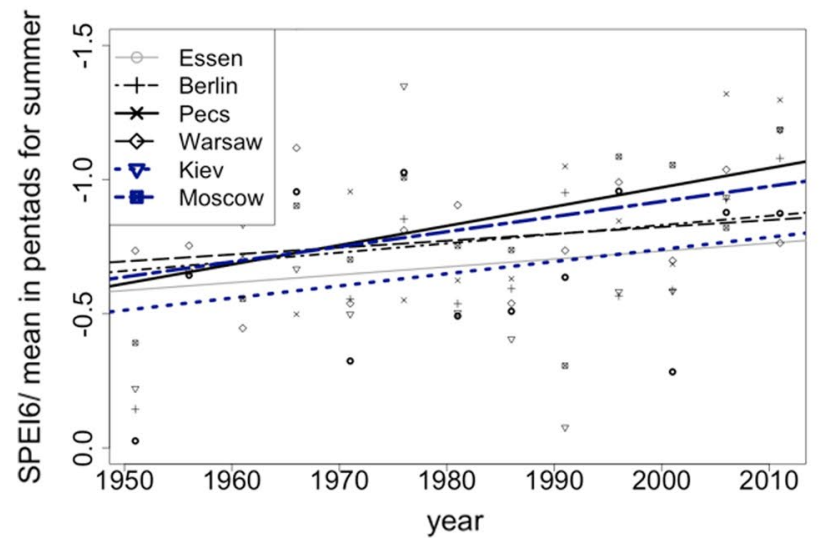

Fig. 7 The average SPEI index for pentads for the a 1-month, b 3-month, and c 6-month timescales, for all events with an indicator value below 0 , in the summer months-June, July and August

would not give a full picture of the real conditions. This is also associated with the fact that in the investigated region, summer precipitation very often falls as torrential rains,
Table 4 Simple linear regression parameters fitted to the negative summertime SPEI values averaged for 5-year periods (pentads) for the 1-, 3- and 6-month timescales for all the stations included in the analysis (the trends of summer drought severity are presented in Fig. 13)

\begin{tabular}{llrrr}
\hline & Parameter & \multicolumn{1}{l}{ SPEI1 } & \multicolumn{1}{l}{ SPEI3 } & \multicolumn{1}{l}{ SPEI6 } \\
\hline ESSEN & $R^{2}$ & 0.053 & -0.088 & -0.060 \\
& $a$ & -0.005 & -0.001 & -0.003 \\
BERLIN & $R^{2}$ & 0.014 & 0.200 & -0.051 \\
& $a$ & -0.003 & -0.007 & -0.003 \\
PÉCS & $R^{2}$ & 0.207 & -0.075 & 0.132 \\
& $a$ & -0.007 & 0.001 & -0.007 \\
\multirow{2}{*}{ WARSAW } & $R^{2}$ & -0.073 & -0.057 & -0.023 \\
& $a$ & 0.001 & -0.002 & -0.003 \\
KIEV & $R^{2}$ & -0.049 & -0.089 & -0.024 \\
& $a$ & 0.004 & -0.001 & -0.005 \\
\multirow{2}{*}{ MOSCOW } & $R^{2}$ & 0.085 & 0.008 & 0.085 \\
& $a$ & 0.005 & -0.004 & -0.006 \\
\hline
\end{tabular}

$R^{2}$ coefficient of determination, calculated using Pearson's correlation, $a$ linear regression slope

which, even though they are very intense and result in high monthly totals, are short and most of the water is lost due to runoff. The negative values of the SPEI index were filtered for the selected time interval (summer months), and then the average values of the index in pentads were calculated. The trends obtained from fitting the linear regression to the mean values of the summer SPEI in pentads are shown in Fig. 7. For SPEI1 (1-month timescale), an increasing trend of drought severity in the summer was determined for Essen, Berlin and Pécs, wherein such a trend was the most pronounced for this timescale in Pécs. The SPEI for the 3-month timescale for Pécs was also positive, but it also became positive for Warsaw, Kiev and Moscow. The average SPEI for the 6-month timescale for all stations indicates an increase in the severity of drought over time, with the greatest increase in its intensity during the summer in Pécs (highest linear regression slope value).

\subsection{Discussion}

Referring to the analyzes carried out by Spinoni et al. (2019) on a regional scale, based on the SPI index for a 12-month timescale, it was forecasted that both the precipitation amount as well as the value of the indicator itself will most probably increase in Germany, Russia and Ukraine in the future. According to the same study, an increase in the precipitation amount is also expected in Poland and Hungary. 
However, in Poland, the 12-month timescale SPI index analysis showed a positive trend of this indicator value, which suggests a tendency to wetter conditions, whereas in Hungary, a trend toward drought was expected. Nevertheless, the SPEI index for the12-month timescale predicts a decline in the value of that index in Poland, Germany and Hungary, where the potential evapotranspiration is also expected to increase.

In the presented study, a similar investigation was carried out but it was a point analysis (considering a few locations in a temperate zone in Europe, not a spatial distribution), and was based on drought indices calculated for shorter timescales (1-, 3- and 6-months). Moreover, thermal and precipitation data allowed the calculation of potential evapotranspiration which showed an increasing trend for all the locations, which is consistent with the results of Spinoni et al. (2019). The most noticeable upward trend of potential evapotranspiration was found for Kiev. This translates into a slight increase in the drought strengthening-according to the SPEI, an increase in the severity of droughts was shown (Fig. 7). Significant and positive trends in the increase in the average annual air temperature were also determined for all sites, with the strongest increasing trend for Moscow. Regarding available datasets, the obtained results indicated an increasing trend in precipitation in Warsaw, while a decreasing trend occurred in Berlin at the same time, which is only partly in agreement with the study of Spinoni et al. (2019). In Kiev and Pécs, long-term precipitation trends were statistically insignificant, thus indicating neither a reduction nor an increase in the amount.

The SPEI and SPI indices can be computed for different timescales (Vicente-Serrano et al. 2010; Beguería and VicenteSerrano 2017a, b). The multi-scalar character of these two indices is their important advantage compared to other existing indices (Vicente-Serrano et al. 2012). Such an approach allows estimation of the influence of past thermal and humidity conditions in drought analysis. Thus, computation enabled the index to adapt to the memory of the system under study in terms of the intended purpose of the research (meteorological, agriculture-soil, hydrological drought detection). The quantity of this memory is controlled by the parameter scale (VicenteSerrano et al. 2010; Beguería and Vicente-Serrano 2017a, b). It was shown that short timescales ( 1 or 3 months) can be used to describe meteorological drought while a 3-month or 6-month scale is usually used to evaluate an agricultural drought, and a longer scale, such as 12 or 24 months, is more suitable for investigating hydrological drought and water resources (Mishra and Singh 2010; Pei et al. 2020). For example, the SPEI index for a 6-month scale, calculated for a timeseries in Indonesia presented the best accuracy for modeling soil moisture (95\%) compared to the rest of the timescales used (3-, 6-,12-months) (Ariyanto et al. 2020). Nevertheless, the type of the soil was Alfisol, which has a clay texture and very stable aggregate. In Wang et al.'s (2015) study investigating data from 40 soil moisture stations in China, it was defined that the optimum timescale for monthly SPI and SPEI which shows the most significant correlation with soil moisture at a specific soil layer was the 1-month timescale. On the other hand, their results also suggest an increasing, direct proportional relationship between the length of the index timescale and the depth of the soil for which the moisture content is measured. By using indices in three different timescales in this study we presented trends for the occurrence of drought and its severity regarding meteorological and soil (agricultural) drought, where it was assumed that the 1- and 3-month timescales are the most suitable for predicting meteorological drought, whereas the 6-month timescale is best for detecting soil drought.

The increase in the average annual temperature as well as the potential evapotranspiration at all stations translates into the results obtained for the SPEI index, however, the irregular distribution of precipitation throughout the year with a generally increasing tendency of its total annual value, makes determining drought risk more complex.

Taking into consideration all the months when the SPI and SPEI indices dropped below - 1 (representing dry periods/ drought conditions), an analysis of the trends in the occurrence of drought was performed in this study. An increasing trend in the occurrence of drought has been determined for the SPEI index for all considered timescales. It is worth emphasizing that according to this indicator, for the last five years included in this study, i.e. 2011-2015, an incomparably higher number of droughts has occurred, compared to previous pentads since 1951. However, in the latest study by Stagge et al. (2017), it was found that drought trends in continental Europe show that the total area experiencing an SPI6 drought has decreased significantly during the last 56 years which contradicts previous studies. Also, in the same study, spatial patterns of drought occurrence investigated by the SPI6 index turned out to be similar to the results obtained by the SPEI for a 6-month scale, showing an increasing drought occurrence across southern Europe and the Mediterranean area, while decreasing for broad parts of northern 
Europe (Stagge et al. 2017). Another recent study also showed that the SPEI is probably a more suitable index than the SPI to investigate the spatio-temporal variability of drought in Europe under climate change, especially for Mediterranean region and Central Europe (Ionita and Nagavciuc 2021). Moreover, this same study suggests that the increasing mean air temperature and the potential evapotranspiration can enhance drought intensity over the southern and central parts of Europe. In light of the projected increase in potential evapotranspiration in a warming climate, this result has implications regarding the future occurrence of drought (Ionita and Nagavciuc 2021). In Spinoni et al.'s (2018) study regarding the RCP4.5 emission scenario (which for the end of the twenty-first century assumes a $\mathrm{CO}_{2}$ equivalent of about $650 \mathrm{ppm}$ ), it was predicted that over the period 2011-2100 in Central Europe, a moderate increase in drought frequency will occur on an annual scale. Then, under scenario RCP8.5 (the equivalent of about $1370 \mathrm{ppm}$ ), a strong increase in drought frequency in most of the region was predicted, with an increase in drought occurrence mainly over the summer. These two scenarios correspond to global temperature increases of approximately 1.8 and $4.0^{\circ} \mathrm{C}$, respectively, compared to past conditions.

The severity of drought varied depending on the temporal scale used to calculate both indicators. Nevertheless, an increasing trend in drought severity for the 6-month timescale was identified for the SPEI indicator for all stations during the summer. In regions that already experience difficulties with water resources, being below or close to zero climatic water balance, as indicated in this study in the cases of Berlin, Warsaw and Pécs, can cause problems associated with crop irrigation as well as worsening biometeorological human health conditions. The awareness of the impact of drought on human health is reflected in the development of this branch of medicine which is currently becoming an independent field of science. In our study, the average SPEI index for pentads showed that considering the SPEI indicator for three different timescales (1-, 3- and 6- months), the 6-month timescale appeared to present the most pronounced trend of increasing drought severity across all the investigated stations. Therefore, it can be assumed that agrometeorological drought (soil drought) will most probably show an increasing trend in the mid latitudes of Europe.

It has been stated in IRC technical reports on meteorological drought in Europe by Spinoni et al. (2016) that due to climate change and the ever-increasing pressure on water resources, the effects of droughts are likely to be more severe in the future. Consequently, they will require constant monitoring, evaluation and adaptation (Spinoni et al. 2016).

Even though a cyclical nature of drought occurrence in 5-year periods was found (SPI index), the role of an increase in the average annual air temperature by more than 1 degree at each site over 65 years should not be neglected. This is reflected well in the higher number of droughts indicated by the SPEI in 2010-2015 which leads to the assumption that, even with the cyclical occurrence of certain climate features (precipitation pattern), the overall effect on drought occurrence and severity is enhanced by other factors, such as the already mentioned increase in the average annual temperature and thus intensified potential evaporation.

Even though the fluctuations in the number of dry periods were noticeable as indicated by the SPI index, which is solely based on precipitation data, the number of droughts in the most recent period (2011-2015) was the highest since 1976 and higher than ever before in the period under analysis for the SPEI. The negative effects of global climate change are still enhanced by anthropogenic activities (constantly increasing emissions), which are most profoundly noticeable as an increase in air temperature. Sometimes two (or more) climate extremes can mutually strengthen each other (Seneviratne et al. 2012a, b). Then, a positive feedback occurs between the two extremes. For example, there can be the mutual enhancement of droughts and heatwaves in transitional regions between dry and wet climates. This feedback has been recognized as having an impact on predicted changes in temperature variability and heatwave occurrence in, among others, Central and Eastern Europe (Seneviratne et al. 2012a, b). Thus, one can expect a greater number of more intense droughts in the future, for which the indicators combining precipitation and thermal conditions will be more sensitive. Further "flattening" of the probability distribution of drought indices, as in the example presented on the hexagonal surface plots for Warsaw and Pécs regarding the SPEI indicator, is also expected, which means the more frequent occurrence of very dry and very wet periods causing more extreme events.

\section{Appendix}

See Figs. 8, 9, 10, 11, 12, 13. 

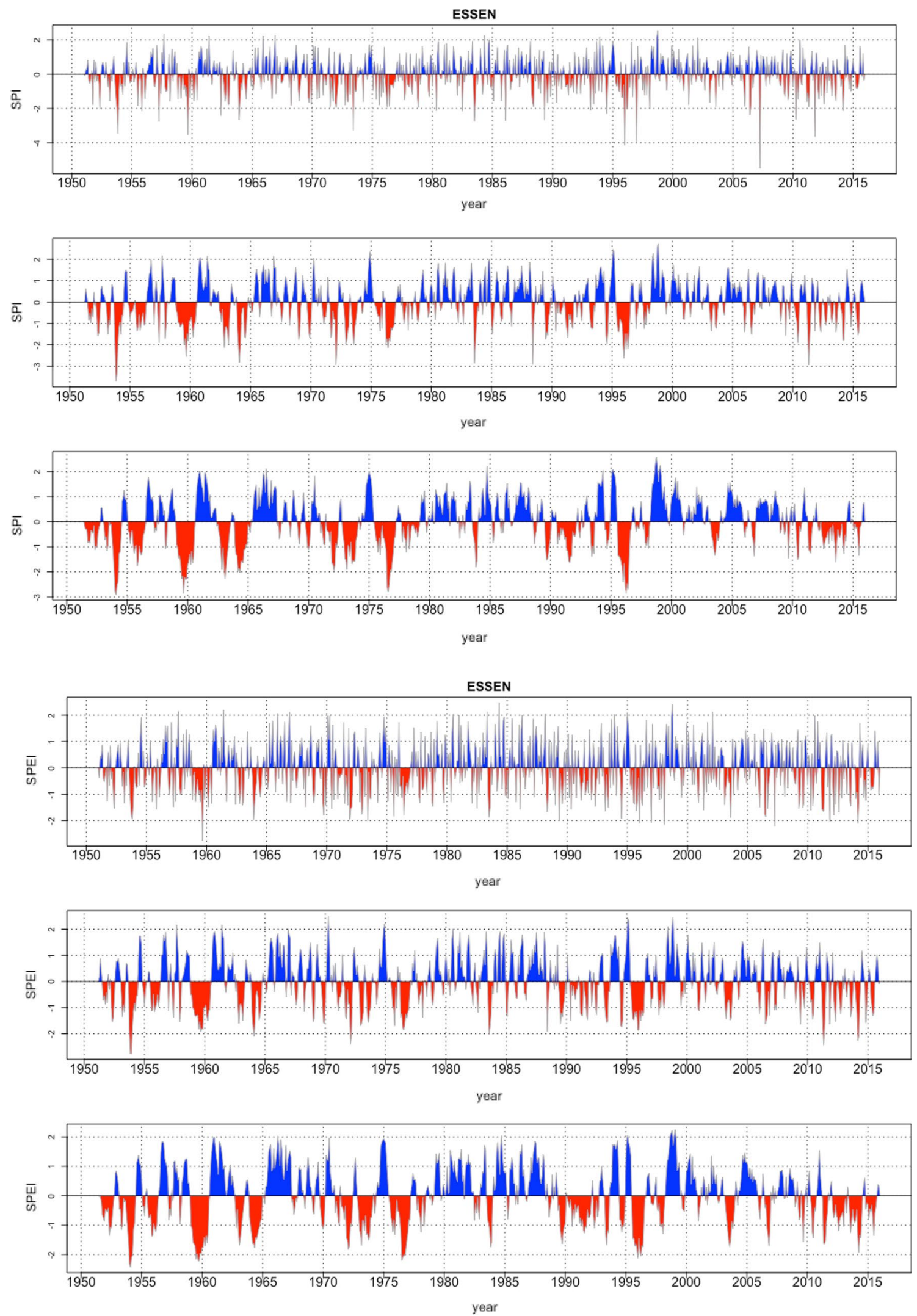

Fig. 8 Long-term (1951-2015) index values a SPI on a 1-, 3-, and 6-month scale, and b SPEI on a 1-, 3-, and 6-month scale for Essen 

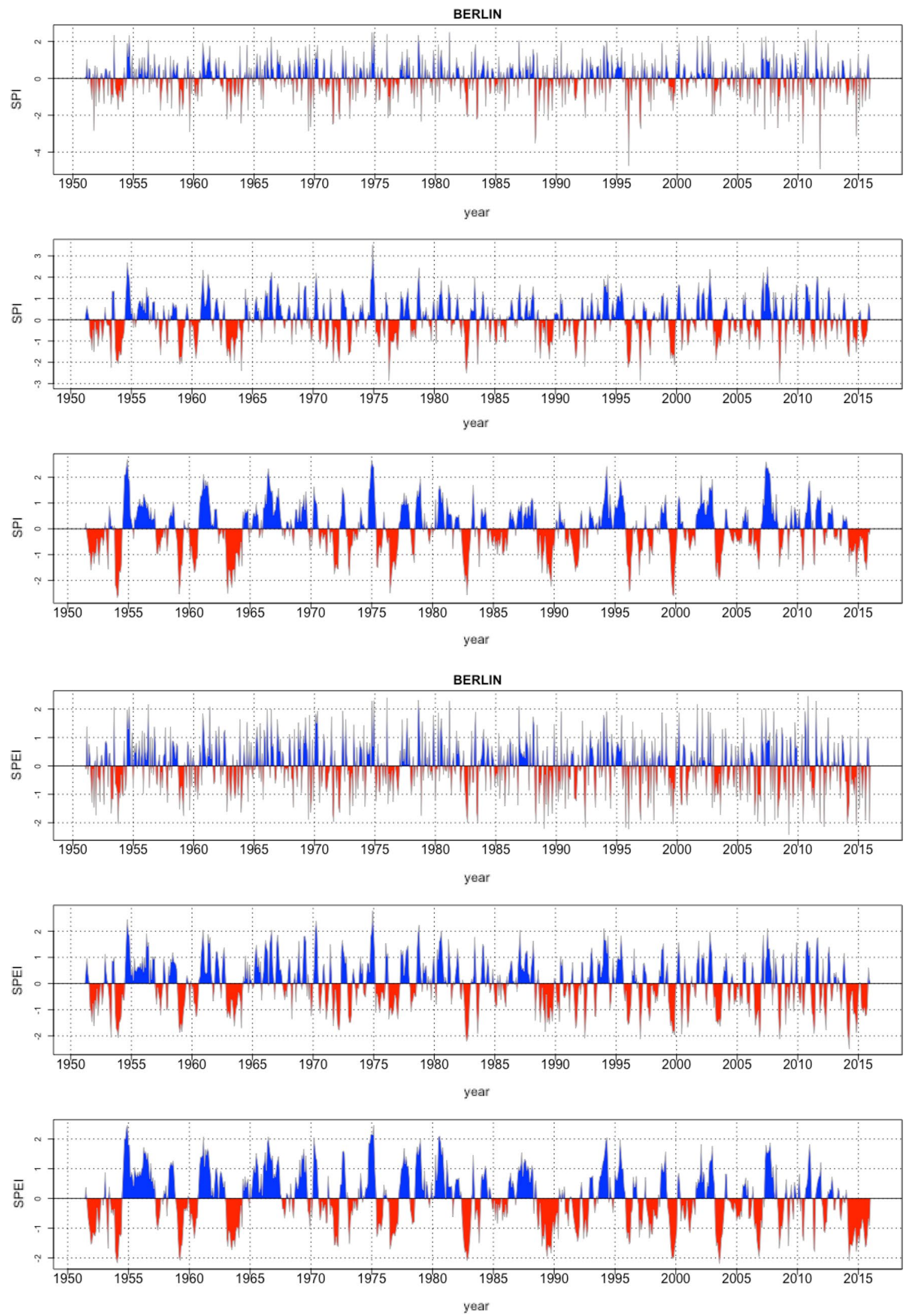

Fig. 9 Long-term (1951-2015) index values a SPI on a 1-, 3-, and 6-month scale, and b SPEI on a 1-, 3-, and 6-month scale for Berlin 

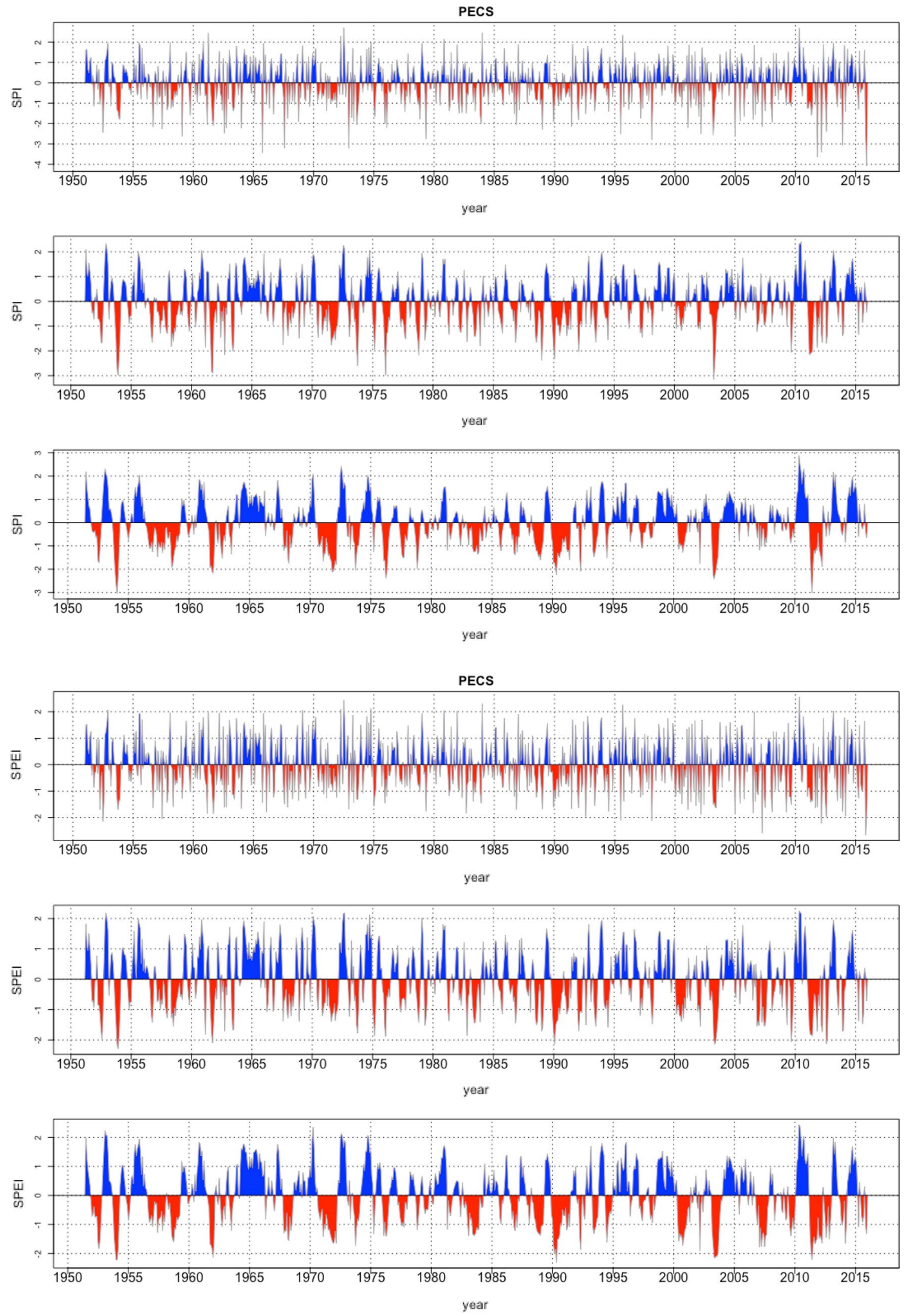

Fig. 10 Long-term (1951-2015) index values a SPI on a 1-, 3-, and 6-month scale, and b SPEI on a 1-, 3-, and 6-month scale for Pecs 

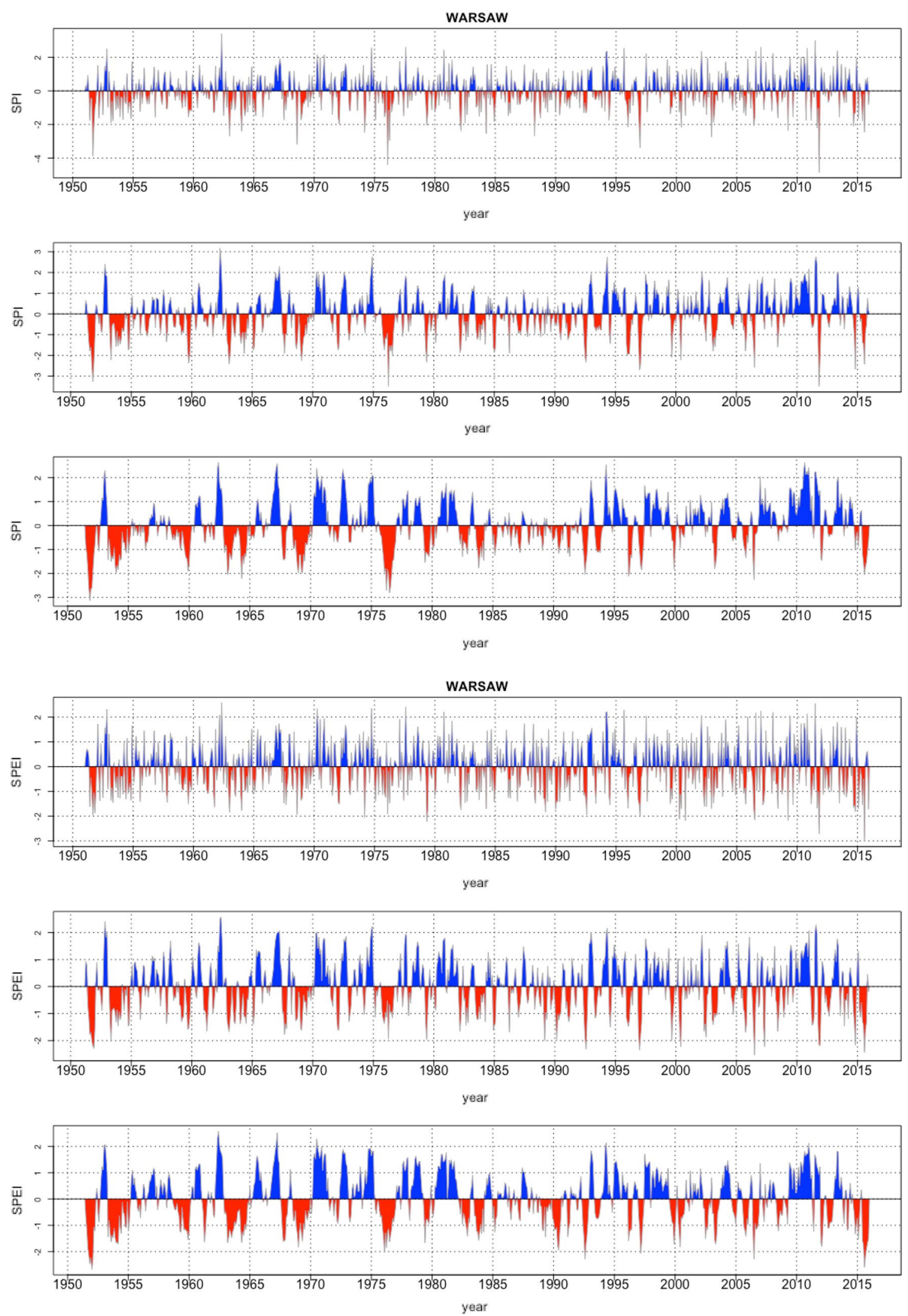

Fig. 11 Long-term (1951-2015) index values a SPI on a 1-, 3-, and 6-month scale, and b SPEI on a 1-, 3-, and 6-month scale for Warsaw 

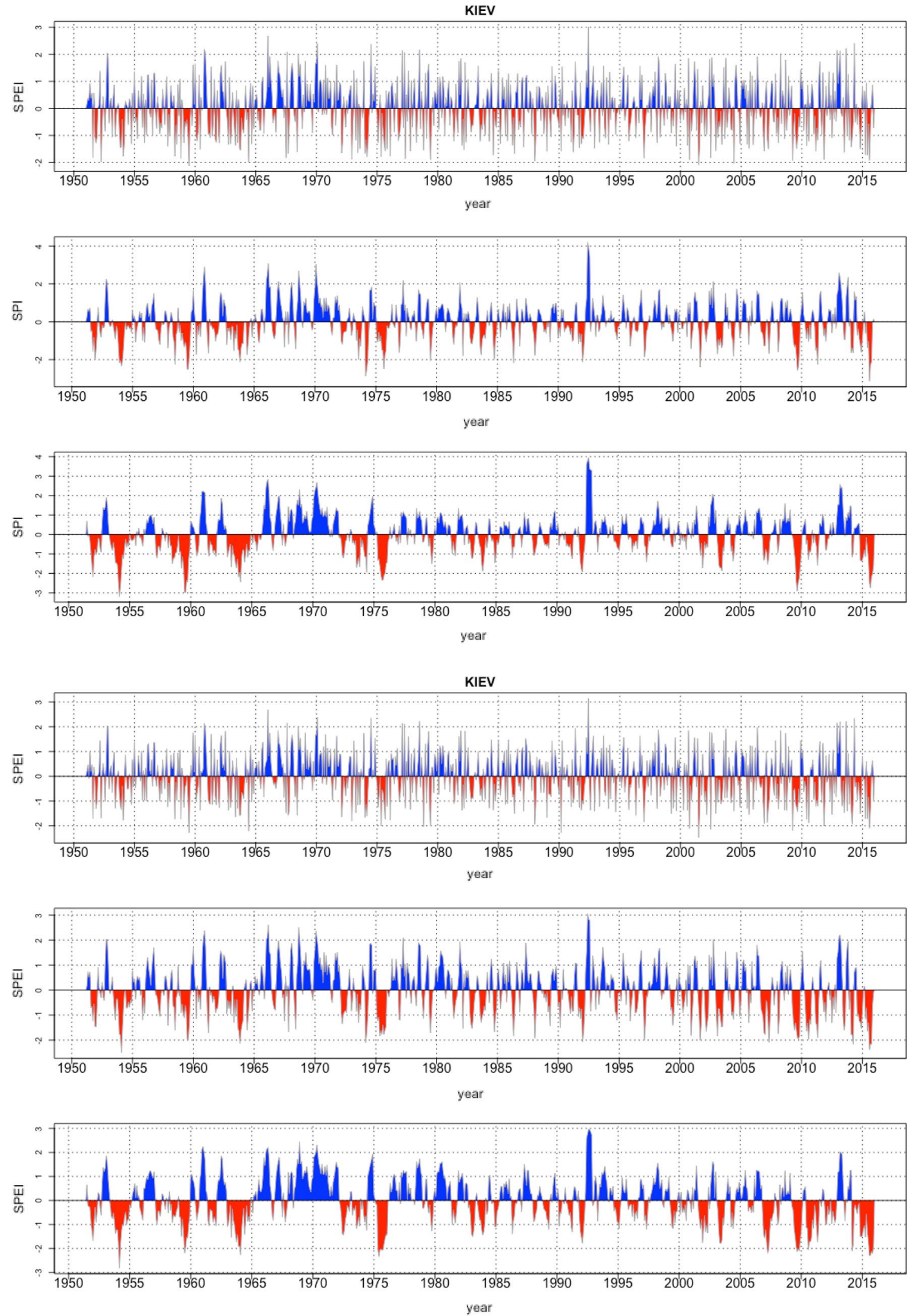

Fig. 12 Long-term (1951-2015) index values a SPI on a 1-, 3-, and 6-month scale, and b SPEI on a 1-, 3-, and 6-month scale for Kiev 

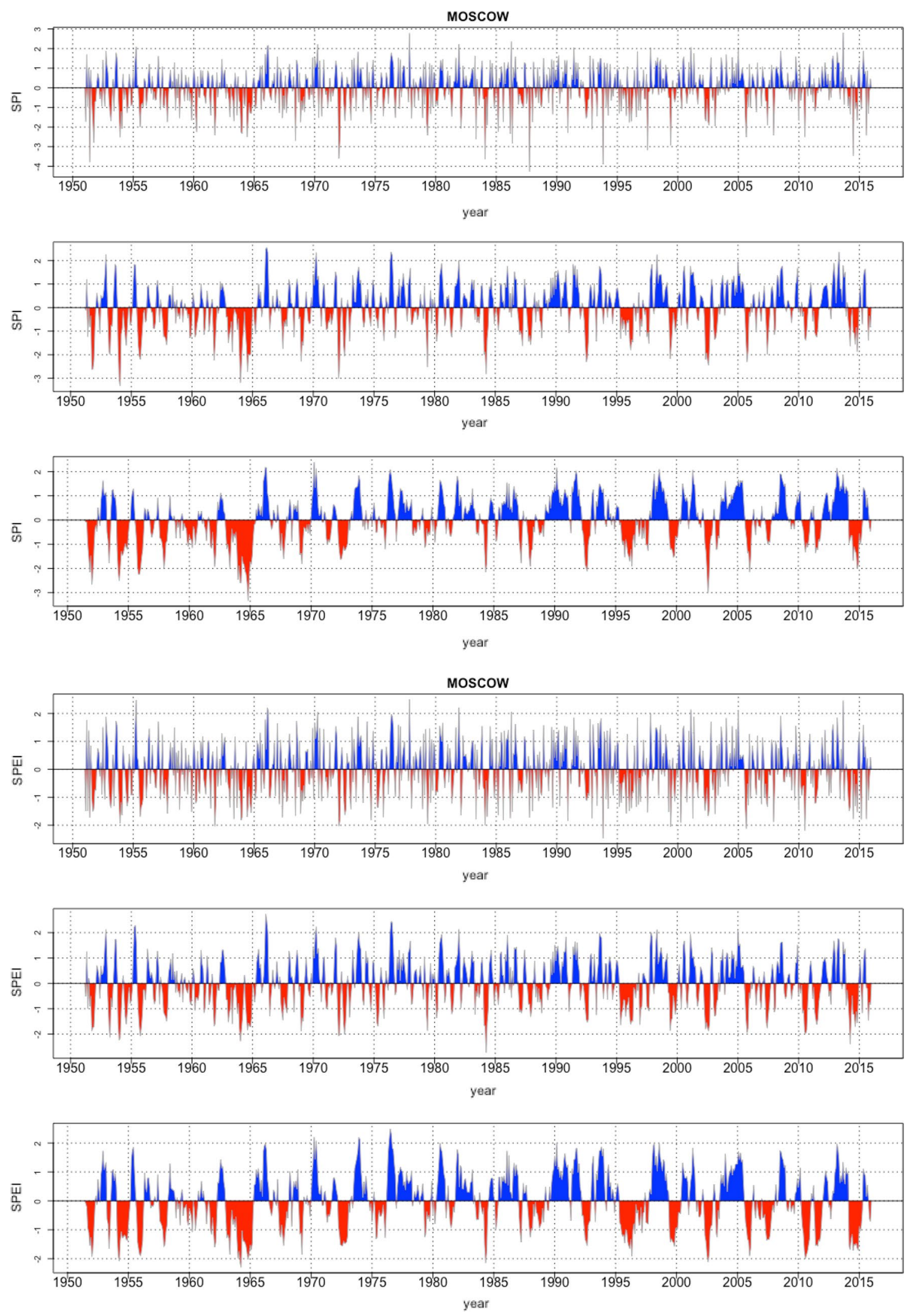

Fig. 13 Long-term (1951-2015) index values a SPI on a 1-, 3-, and 6-month scale, and b SPEI on a 1-, 3-, and 6-month scale for Moscow 
Funding Not applicable.

Data availability statement The climatological data that support the findings of this study during manuscript preparation were available from the portal of European Climate Assessment \& Dataset project and Polish Institute of Meteorology and Water Management portal (IMGIW), under links: https://www.ecad.eu and https://danepublic zne.imgw.pl.

Availability of data and material The data used in this paper are in the public domain: https://www.ecad.eu//dailydata/index.php and https:// dane.imgw.pl/data/dane_pomiarowo_obserwacyjne/dane_meteorolog iczne/dobowe/klimat/.

Code availability Not applicable.

\section{Declarations}

Conflict of interest The authors declare no conflict of interest.

Open Access This article is licensed under a Creative Commons Attribution 4.0 International License, which permits use, sharing, adaptation, distribution and reproduction in any medium or format, as long as you give appropriate credit to the original author(s) and the source, provide a link to the Creative Commons licence, and indicate if changes were made. The images or other third party material in this article are included in the article's Creative Commons licence, unless indicated otherwise in a credit line to the material. If material is not included in the article's Creative Commons licence and your intended use is not permitted by statutory regulation or exceeds the permitted use, you will need to obtain permission directly from the copyright holder. To view a copy of this licence, visit http://creativecommons.org/licenses/by/4.0/.

\section{References}

Ariyanto DP, Aziz A, Komariah et al (2020) Comparing the accuracy of estimating soil moisture using the standardized precipitation Index (SPI) and the standardized precipitation evapotranspiration index (SPEI). Sains Tanah 17:23-29. https://doi.org/10.20961/ stjssa.v17i1.41396

Beguería S, Vicente-Serrano SM, Angulo-Martínez M (2010) A multiscalar global drought dataset: the SPEI base: a new gridded product for the analysis of drought variability and impacts. Bull Am Meteorol Soc 91:1351-1356. https://doi.org/10.1175/2010B AMS2988.1

Beguería S, Vicente-Serrano SM, Reig F, Latorre B (2014) Standardized precipitation evapotranspiration index (SPEI) revisited: parameter fitting, evapotranspiration models, tools, datasets and drought monitoring. Int J Climatol 34:3001-3023. https://doi.org/ 10.1002/joc. 3887

Beguería S, Vicente-Serrano SM (2017) SPEI: calculation of the standardised precipitation-evapotranspiration index. R package

Beguería S, Vicente-Serrano SM (2017) Package 'SPEI'. Calculation of the Standardised Precipitation-Evapotranspiration Index

Bezdan J, Bezdan A, Blagojević B et al (2019) SPEI-based approach to agricultural drought monitoring in Vojvodina region. Water (switzerland). https://doi.org/10.3390/w11071481

Blain GC (2011) Standardized precipitation index based on pearson type III distribution. Rev Bras Meteorol 26:167-180. https://doi. org/10.1590/s0102-77862011000200001
Collins R, Kristenses K, Thyssen N (2009) Water resources across Europe - confronting water scarcity and drought. EEA Report 2/2009. Denmark. https://doi.org/10.2800/16803

ECAD (2018) Home European Climate Assessment \& Dataset portal

Faustin Katchele O, Ma ZG, Yang Q, Batebana K (2017) Comparison of trends and frequencies of drought in central North China and sub-Saharan Africa from 1901 to 2010. Atmos Ocean Sci Lett 10:418-426. https://doi.org/10.1080/16742834.2017.1392825

Faye C, Grippa M, Wood S (2019) Use of the Standardized Precipitation and Evapotranspiration Index (SPEI) from 1950 to 2018 to determine drought trends in the Senegalese territory, Climate Change

Hayes MJ, Svoboda MD, Wilhite DA, Vanyarkho OV (1999) Monitoring the 1996 drought using the Standardized Precipitation Index. Bull Am Meteor Soc 31:429

Hayes MJ, Svoboda MD, Wardlow BD et al (2012) Drought monitoring: Historical and current perspectives. Remote Sens Drought Innov Monit Approach. https://doi.org/10.1201/b11863

Hosking JRM (1986) The theory of probability weighted moments. Res Rep RC 12210 IBM Res Div Yorkt Height NY 10598

Ionita M, Nagavciuc V (2021) Changes in drought features at European level over the last 120 years. Nat Hazards Earth Syst Sci. https:// doi.org/10.5194/nhess-2021-46

IPCC 2001: climate change (2001) Contribution of working group I to the third assessment report of the intergovernmental panel on climate change [Houghton, J.T. Ding, Y. Griggs, D.J. Noguer, M. Linden, P.J. van der Dai, X. Maskell, K. Johnson, C.A.]. Cambridge Univ Press, p 94

Kottek M, Grieser J, Beck C et al (2006) World map of the KöppenGeiger climate classification updated. Meteorol Zeitschrift 15:259-263. https://doi.org/10.1127/0941-2948/2006/0130

Kożuchowski K, Wibig J, Degirmendžić J (2012) Meteorologia i Klimatologia, Wydawnictwo Naukowe PWN. Warsaw

Krajinović Z (2010) Implementation of standardised precipitation index-SPI, Republic Hydrometeorological Service of Serbia

Livada I, Assimakopoulos VD (2007) Spatial and temporal analysis of drought in Greece using the Standardized Precipitation Index (SPI). Theor Appl Climatol 89:143-153. https://doi.org/10.1007/ s00704-005-0227-z

Lloyd-Hughes B, Saunders MA (2002) A drought climatology for Europe. Int J Climatol 22:1571-1592. https://doi.org/10.1002/ joc. 846

McKee TBJ, Nolan JK (1993) The relationship of drought frequency and duration to time scales. In: Prepr eighth conf appl climatol Anaheim, CA, Amer Meteor, Soc pp 179-184

McKee TBJ, Nolan JK (1995) Drought monitoring with multiple time scales. In: Prepr ninth conf appl climatol Dallas, TX, Amer Meteor Soc, pp 233-236

Mishra AK, Singh VP (2010) A review of drought concepts. J Hydrol 391:202-216. https://doi.org/10.1016/j.jhydrol.2010.07.012

Pei Z, Fang S, Wang L, Yang W (2020) Comparative analysis of drought indicated by the SPI and SPEI at various timescales in Inner Mongolia, China. Water (switzerland). https://doi.org/10. 3390/w12071925

R Core Team (2020) R: a language and environment for statistical computing

Rhee J, Im J, Carbone GJ (2010) Monitoring agricultural drought for arid and humid regions using multi-sensor remote sensing data. Remote Sens Environ 114:2875-2887

Seneviratne SI, Nicholls N, Easterling D, Goodess CM, Kanae S, Kossin J, Luo Y, Marengo J, McInnes MRK, Reichstein M, Sorteberg A, Vera C, Zhang X (2012a) Changes in climate extremes and their impacts on the natural physical environment in book: managing the risks of extreme events and disasters to advance climate change adaptation (SREX). In: Field CB, Barros V, Stocker TF, Qin D, Dokken DJ, Ebi KL, Mastrandrea MD, Mach KJ, Plattner 
SKA, Tignor M, PMM (eds) A special report of working groups I and II of the Intergovernmental Panel on Climate Change (IPCC). Cambridge University Press, Cambridge, pp 109-230

Seneviratne SI, Nicholls N, Easterling D et al (2012b) Changes in climate extremes and their impacts on the natural physical environment. Manag Risks Extrem Events Disasters Adv Clim Chang Adapt Spec Rep Intergov Panel Clim Chang 9781107025:109230. https://doi.org/10.1017/CBO9781139177245.006

Singh VP et al (1993) Parameter estimation for 3-parameter log-logistic distribution (LLD3) by Pome. Stoch Hydrol Hydraul 7:163-177

Spinoni J, Naumann G, Vogt JV, Barbosa P (2015) The biggest drought events in Europe from 1950 to 2012. J Hydrol Reg Stud 3:509524. https://doi.org/10.1016/j.ejrh.2015.01.001

Spinoni J, Naumann G, Vogt J, Barbosa P (2016) Meteorological droughts in europe: events and impacts-past trends and future projections. Publ off Eur Union. Luxemb. EUR 27748 EN. https:// doi.org/10.2788/450449

Spinoni J, Vogt JV, Naumann G et al (2018) Will drought events become more frequent and severe in Europe? Int J Climatol 38:1718-1736. https://doi.org/10.1002/joc.5291

Spinoni J, Barbosa P, De Jager A et al (2019) A new global database of meteorological drought events from 1951 to 2016. J Hydrol Reg Stud 22:100593. https://doi.org/10.1016/j.ejrh.2019.100593

Stagge JH, Kingston DG, Tallaksen LM, Hannah DM (2017) Observed drought indices show increasing divergence across Europe. Sci Rep 7:1-10. https://doi.org/10.1038/s41598-017-14283-2

Thornthwaite CW (1948) An approach toward a rational classification of climate. Geogr Rev 38:55-94

Trnka M, Semerádová D, Novotný I et al (2016) Assessing the combined hazards of drought, soil erosion and local flooding on agricultural land: a Czech case study. Clim Res 70:231-249. https:// doi.org/10.3354/cr01421
Tsakiris G, Vangelis H (2005) Establishing a Drought Index incorporating evapotranspiration. Eur Water 9(10):3-11

Vicente-Serrano SM, Beguería S, López-Moreno JI (2010) A multiscalar drought index sensitive to global warming: the standardized precipitation evapotranspiration index. J Clim 23:1696-1718. https://doi.org/10.1175/2009JCLI2909.1

Vicente-Serrano SM, Beguería S, Lorenzo-Lacruz J et al (2012) Performance of drought indices for ecological, agricultural, and hydrological applications. Earth Interact. https://doi.org/10.1175/2012E I000434.1

Vogt JV, Somma F (eds) (2000) Drought and drought mitigation in Europe. Kluwer Acad Publ Dordrecht, Netherlands, p 336

Vogt JV, Barbosa P, Hofer B, Magni D, De Jager A, Singleton A, Horion S, Sepulcre G, Micale F, Sokolova E, Calcagni L, Marioni M, Antofie TE (2011) Developing a European drought observatory for monitoring, assessing and forecasting droughts across the European continent. AGU Fall Meet Abstr 1, NH24A-07

Wang H, Rogers JC, Munroe DK (2015) Commonly used drought indices as indicators of soil moisture in China. J Hydrometeorol 16:1397-1408. https://doi.org/10.1175/JHM-D-14-0076.1

Wang Q, Zeng J, Qi J et al (2020) A multi-scale daily SPEI dataset for drought monitoring at observation stations over the mainland China from 1961 to 2018. Earth Syst Sci Data Discuss. https:// doi.org/10.5194/essd-2020-172

Woś A (2010) Klimat polski w drugiej połowie XX wieku. Wydawnictwo Naukowe UAM, Poznań

Publisher's Note Springer Nature remains neutral with regard to jurisdictional claims in published maps and institutional affiliations. 